\title{
○ Método de Ilizarov -
princípios e indicacóes
na prática veterinária
}

- Ilizarov method - principles and indications in the veterinary practice

\author{
* Sheila Canevese Rahal ${ }^{1}$-CRMV-SPn. ${ }^{0} 3814$ \\ Reinaldo dos Santos Volpi ${ }^{2}-$ CRM-SPn. ${ }^{0} 29.294$ \\ 1 Médica Veterinária, Profa. Ass. Dra. - Departamento de \\ Cirurgia e Anestesiologia Veterinária - FMVZ, UNESP Botucatu. \\ 2 Médico Ortopedista, Doutor em Cirurgia - Departamento de \\ Ortopedia e Traumatologia - FM, UNESP, Botucatu.
}

\section{RESUMO}

O Método de Ilizarov, baseado em um sistema de fixação externa circular e no conceito da osteogênese por distração gradual, tem permitido o tratamento de diversas afecções ortopédicas complexas. $\mathrm{O}$ artigo aborda seus princípios e algumas indicações em Medicina Veterinária.

Palavras-chave: Ilizarov, osteogênese.

\section{Introdução}

que se conhece hoje internacionalmente como "Método de Ilizarov" é o produto das pesquisas desenvolvidas pelo cirurgião ortopédico russo Gavrijl Abramovich Ilizarov, desenvolvidas em Kurgan - Sibéria, desde 1951. As barreiras da língua e políticas impediram sua maior divulgação no mundo ocidental, o que veio a ocorrer especialmente a partir de 1981, quando a técnica foi adotada na Itália.

O Método de Ilizarov compreende essencialmente:

a) um sistema de fixação esquelética externa, circular, que se une aos ossos por meio de fios finos submetidos à tensão;

b) um conjunto de princípios biológicos denominados "princípios da tensão - estresse", segundo os quais os tecidos submetidos à tração lenta e gradual tornam-se metabolicamente ativos, fenômeno caracterizado pela estimulação das funções proliferativas e biossintéticas das células.
* Faculdade de Medicina Veterinária e Zootecnia - UNESP

Departamento de Cirurgia e Anestesiologia Veterinária

Rubião Júnior $\mathrm{s} / \mathrm{n}$

CEP: 18618-000 - Botucatu - SP Email:sheilacr@fmvz.unesp.br 
a fixação dos fios de transfixação óssea aos anéis, sob tensão;

d) conjunto variado de placas retas, torcidas, placas bandeirinhas e sistemas de dobradiças, para a conexão dos fios aos anéis e também das hastes aos anéis em situações particulares;

e) fios lisos flexíveis, tipo Kirschner, com diâmetros de 1,5 e $1,8 \mathrm{~mm}$ e pinos rosqueados de Schanz (introduzidos pelos autores italianos);

f) tensionador dinamométrico, para a aplicação de tensão aos fios

O número de anéis a serem aplicados depende da natureza da fratura ou osteotomia e da estabilidade inerente ao segmento do membro. Eles são unidos pelas hastes e, pelo aumento ou diminuição da distância, uma progressiva separação ou compressão, respectivamente, pode ser aplicada aos fragmentos ósseos. Para um maior número de aplicações, dobradiças, placas de suporte, montagens de translação ou mecanismos de rotação são acrescentados, permitindo redução e alinhamento de fragmentos em múltiplos planos, simultânea ou consecutivamente. Os fios de Kirschner atravessam o osso e são unidos às armações circulares externas. Quando tensionados os fios podem alcançar a mesma rigidez que os pinos e, por serem finos, minimizam a lesão dos tecidos moles, periósteo e suprimento sangüíneo medular. $\mathrm{O}$ arqueamento dos fios deve ser evitado quando eles forem presos aos anéis; quando aplicada a tensão, o arco transforma-se em reta, provocando desvios dos fragmentos ósseos. Se necessário, para que sejam fixados sem qualquer arqueamento, os fios serão unidos aos anéis por meio de arruelas ou extensões.

Quando adequadamente aplicado, o fixador estabiliza os fragmentos ósseos em todos os planos, mas permite suficiente micromovimento axial para estimular a osteogênese. A estabilidade do fixador interfere no tipo de tecido que preenche o espaço de distração ou foco de fratura, sendo dependente, em parte, do número e da tensão nos fios; do ângulo entre os fios; do número e do tamanho dos anéis; da rigidez do fixador; do formato, área e densidade dos fragmentos ósseos; da quantidade de compressão (ou separação) óssea; do formato, localização e plano de fratura ou osteotomia relativa ao eixo longitudinal do osso; da união dos tecidos miofasciais e ligamentos aos fragmentos, e dos vetores da tensão muscular dentro do membro.

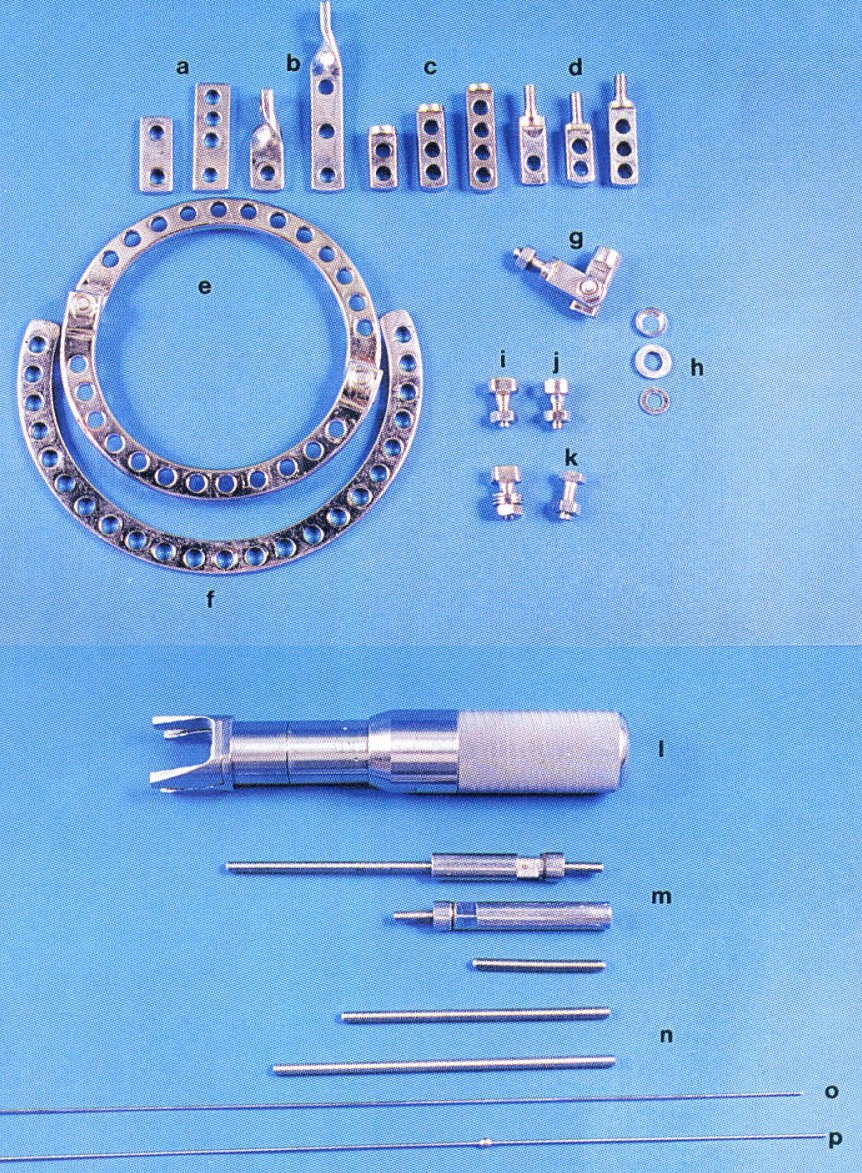

Figura 1. Componentes do fixador de Ilizarov: placas retas (a), placas torcidas (b), bandeiras fêmea (c), bandeiras macho (d), anel (e), semi-anel (5/8) (f), dobradiça $(\mathrm{g})$, arruelas $(\mathrm{h})$, parafuso fixador de fios com canal lateral (i), parafuso fixador de fio com furo central $(j)$, parafuso com cabeça sextavada $(k)$, dinamômetro (l), astes telescópicas (m), hastes rosqueadas (n), fio liso (o), fio com oliva (p).

\section{Aplicações clínicas}

As possibilidades de aplicação clínica do método são numerosas, embora a curva de aprendizado seja particularmente longa, exigindo do cirurgião um treinamento específico, com conhecimento da anatomia transversa dos membros, para a passagem dos fios de transfixação óssea em planos seguros que não coloquem em risco as estruturas vasculares e nervosas.

Entre as indicações já rotineiras em Medicina Veterinária, sobre as quais se fará uma exposição mais detalhada estão:

- alongamento dos membros;

- correção de deformidades dos membros;

- tratamento de perdas ósseas;

- tratamento de fraturas e pseudoartroses; 


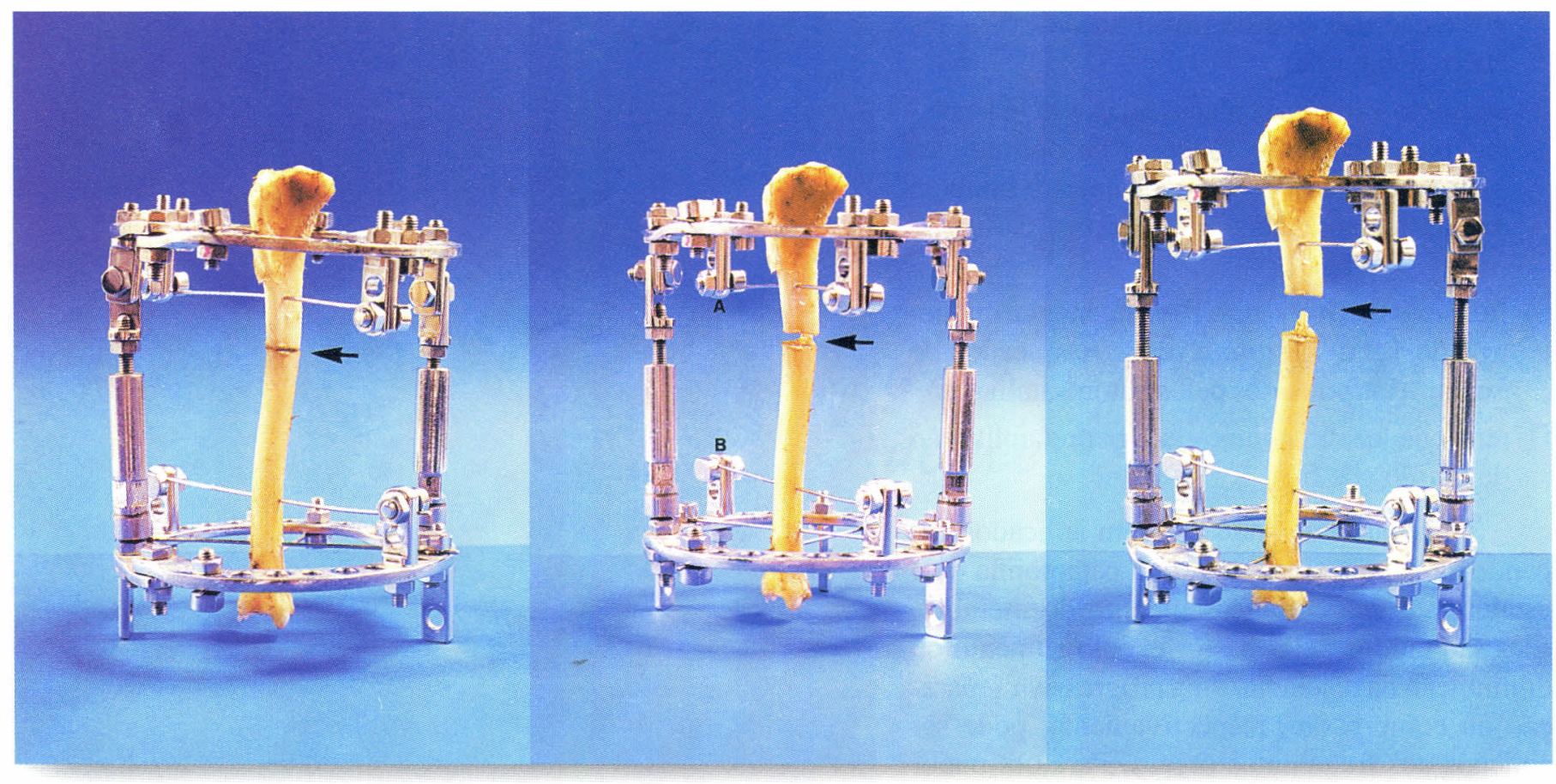

Figura 2. Exemplo da montagem para alongamento tibial. Verificar bandeira com fio proximal (a), bandeira com fio distal (b), foco de distração (seta).

Outras indicações são mencionadas na literatura como: correção de retrognatismo e prognatismo, correção de hipogenesia mandibular, artrodeses e tratamento das osteomielites.

\section{Alongamento dos membros}

A mais notável aplicação do Método de Ilizarov dá-se no alongamento dos membros. Foi nesta particular utilização que ganhou reconhecimento internacional e é nela que melhor se pode compreender os princípios biológicos, já citados, da tensão - estresse, na regeneração dos tecidos. A diferença no comprimento dos membros pode ser resultante de diversos fatores, particularmente das más formações congênitas, como as hemimelias, fechamento precoce da placa de crescimento, consolidações viciosas com cavalgamento dos fragmentos ósseos ou mesmo perda de segmentos ósseos, entre outras causas.

Constatada a dissimetria, clínica e radiográfica, o fixador é previamente montado e adaptado ao objetivo proposto e ao tamanho do animal. Para o alongamento da tíbia e fíbula, por exemplo, usualmente é suficiente uma montagem constituída por dois anéis, um proximal e um distal, unidos por quatro hastes telescópicas (Figura 2). Dois fios de $1,5 \mathrm{~mm}$ transfixam o osso em planos adequados e são conectados sob tensão ao anel proximal, e o mesmo é feito no anel distal. A estabilidade dos fragmentos ósseos fixados é um dos elementos chave na utilização do método e, para isso, o número de anéis e fios deverá ser proporcional ao tamanho do membro e peso do animal. É possível aumentar a estabilidade incluindo um terceiro fio acoplado a cada um dos anéis por meio de uma placa bandeirinha (Figura 2). Este tipo de montagem tem se demonstrado estável para animais de pequeno porte.

Após a aplicação do fixador ao membro, os elementos ósseos devem ser seccionados, para que, por meio do afastamento progressivo promovido entre os anéis seja possível o alongamento. É neste processo de diástase controlada que reside a possibilidade de regeneração do tecido ósseo e das partes moles (Figura 3). Ilizarov descobriu os elementos essenciais para a realização bem sucedida deste processo, que também é conhecido como histogênese por distração, os quais devem ser observados com rigor:

- osteotomia especial ou corticotomia: a osteotomia especializada proposta por Ilizarov, também denominada corticotomia, distintamente da osteotomia tradicional, que implica a secção de todo o osso cortical e do endósteo (às vezes também do periósteo), consiste na secção apenas do osso cortical, preservando intacto o suprimento sangüíneo intramedular, sendo o periósteo elevado e preservado durante o procedimento;

- período de latência: após a realização da corticotomia, um período denominado latência deve ser obser- 


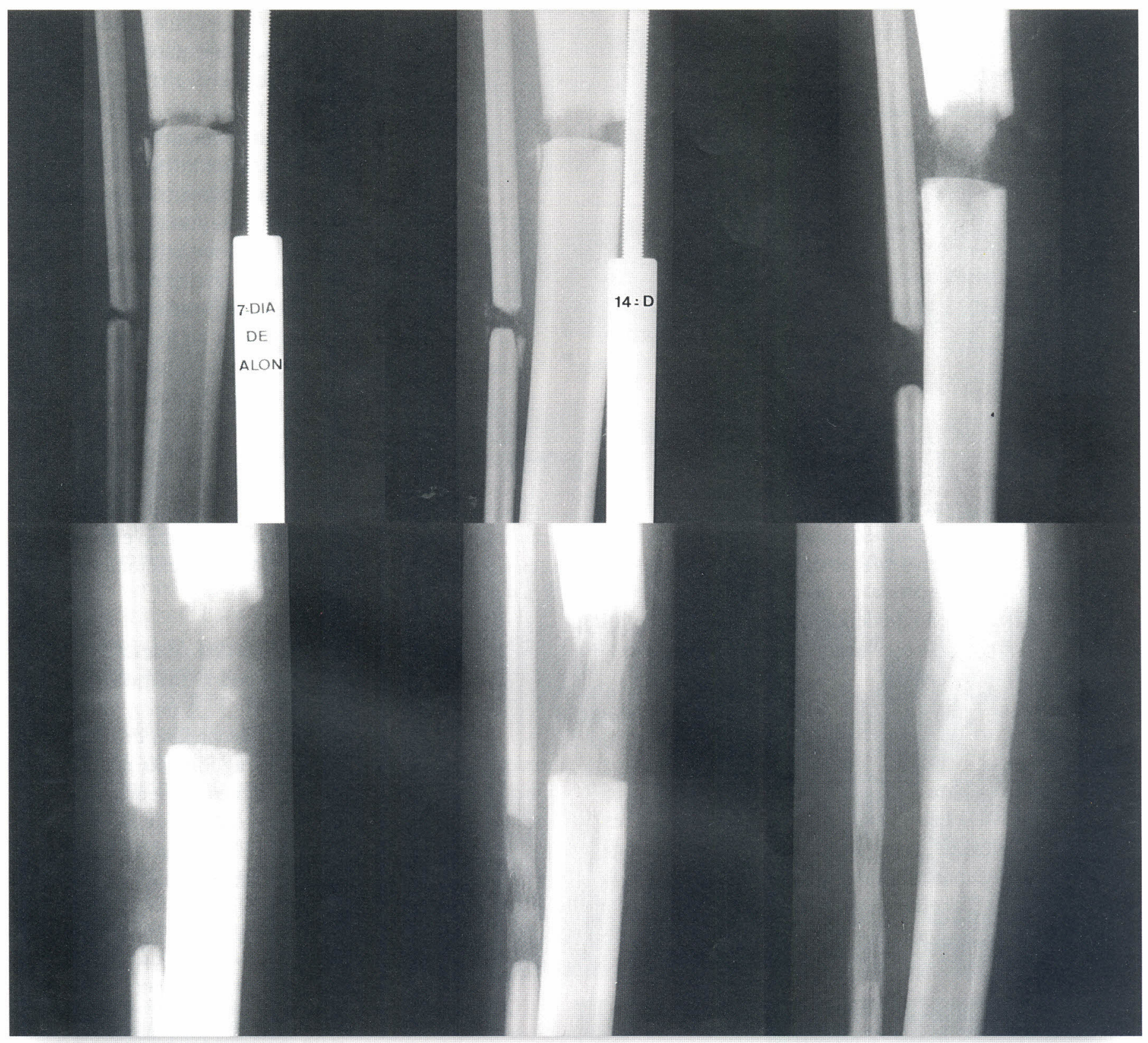

Figura 3. Evolução da regeneração óssea pelo Método de Ilizarov. Observar progressiva diástase dos fragmentos e calcificação do osso neoformado até completa corticalização.

vado antes de se iniciar o alongamento, durante o qual ocorre a organização do hematoma. O tempo proposto para esta latência varia entre três e dez dias, devendo ser mais curto em animais jovens, em corticotomias metafisárias e nas com pouca lesão tecidual;

- magnitude e frequiência da distração: os estudos clínicos e experimentais de Ilizarov demostraram que um alongamento muito rápido produz isquemia na área de distração e, inversamente, um alongamento muito lento, pode produzir consolidação precoce da osteotomia; determinou, baseado nesta experiência, que a magnitude ideal para o alongamento é de um milímetro ao dia, subdivididos em quatro incrementos de $1 / 4$ de milímetro a cada seis horas. Por motivos práticos, muitas vezes se utilizam dois incrementos de $0,5 \mathrm{~mm}$, a cada doze horas, sem maiores prejuízos para a regeneração tecidual;

- fase de consolidação: após completado o alongamento, na magnitude planejada, o fixador é mantido em posição neutra, para permitir a maturação ou consolidação do osso regenerado. Este período é propor- 


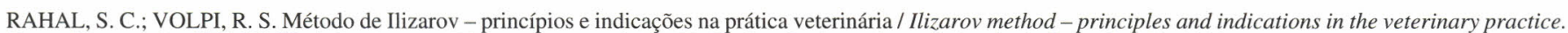
Rev. educ. contin. CRMV-SP / Continuous Education Journal CRMV-SP, São Paulo, volume 3, fascículo 2, p. 54 - 60, 2000.

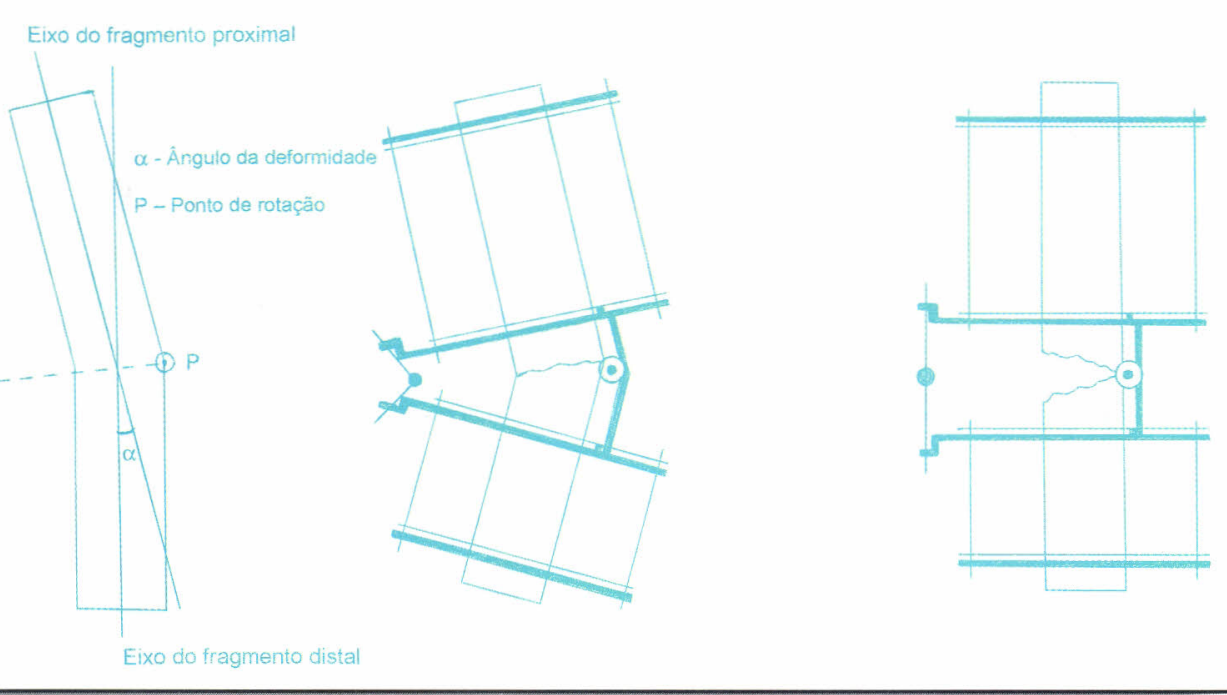

Figura 4. Esquema da aplicação da dobradiça no vértice da deformidade. cional ao alongamento realizado, situando-se em torno de 1 mês por centímetro de alongamento, e deve ser controlado radiograficamente (até se observar a definição de osso cortical na área alongada) e clinicamente pela palpação, podendo o fixador ser removido quando o novo osso estiver forte o suficiente para suportar o peso do animal.

\section{Correção de deformidades angulares}

Outra excelente indicação para a utilização do Método de Ilizarov é a correção de deformidades angulares. Nestes casos, além da observação dos princípios biológicos, já expostos anteriormente, particular atenção deve ser dedicada ao planejamento da construção do fixador propriamente dito, levando-se em conta o exame físico e radiográfico.
O vértice da deformidade deve ser encontrado traçando-se o eixo maior de cada um dos fragmentos ósseos do segmento considerado. O ângulo formado entre esses eixos representa o número de graus da deformidade, no plano considerado. O ponto de rotação dos fragmentos deve coincidir com o vértice da deformidade (deverá corresponder ao local onde devem ser colocadas as dobradiças no fixador externo). A construção do fixador deverá prever a utilização das dobradiças que, ajustadas exatamente no vértice da deformidade, possibilitarão sua correção gradual. A aplicação do fixador pré-construído ao membro e a corticotomia devem obedecer aos princípios já mencionados (Figuras 4 e 5).

\section{Tratamento de perdas ósseas segmentares dos ossos longos}

Perdas ósseas segmentares podem decorrer diretamente de lesões traumáticas agudas ou podem ser o resultado de ressecção de tumores, pseudoartroses infectadas ou osteomielite, entre outras causas. Tradicionalmente, o tratamento dessas falhas é realizado pela adição de enxerto ósseo livre ou vascularizado, acompanhado de fixação interna ou externa.

Com o Método de Ilizarov essas falhas podem ser tratadas por duas diferentes abordagens:

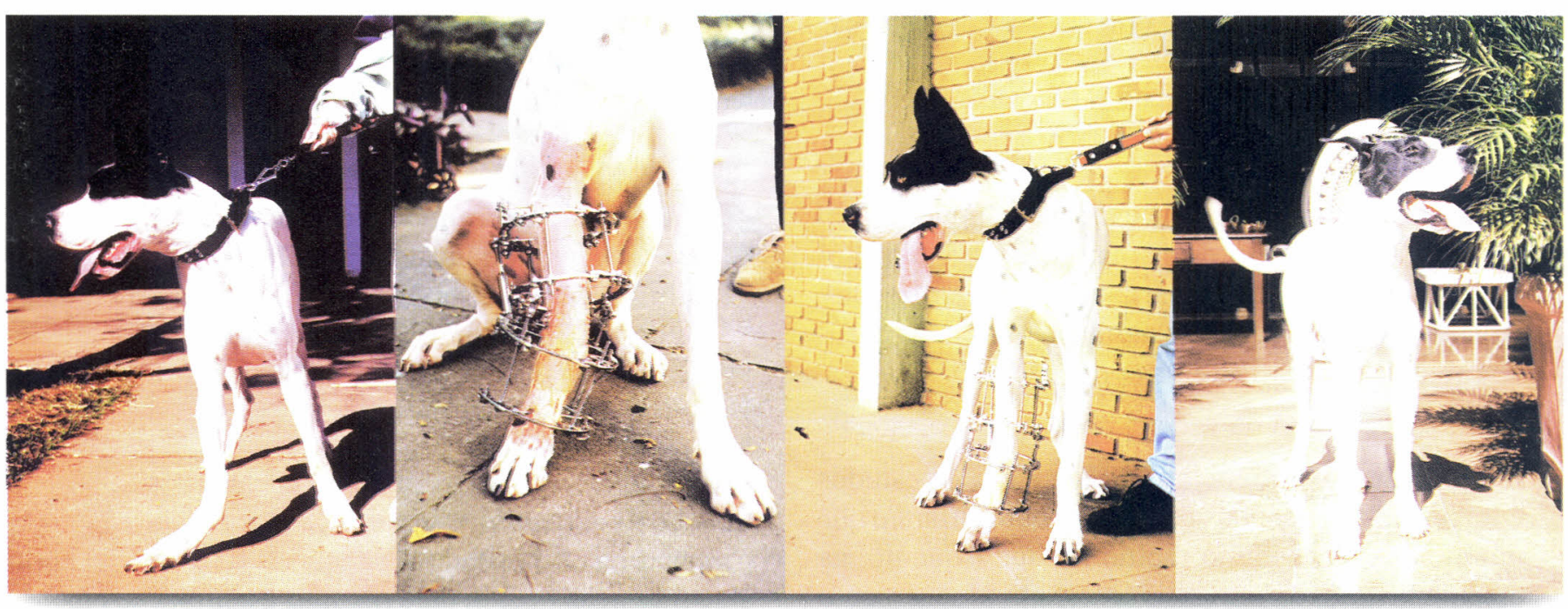

Figura 5. Cão com deformidade valgo-carpiana tratado pelo Método de Ilizarov. Observar a posição das dobradiças. 
- encurtamento agudo do membro no foco da falha óssea, fazendose a aproximação dos fragmentos até que entrem em contato, seguido de alongamento gradual a partir de corticotomia realizada em um ponto distante da falha óssea, preferencialmente em área de osso metafisário, de modo idêntico ao exposto para o alongamento dos membros;

- transporte de um fragmento ósseo, separado da extremidade de um dos segmentos remanescentes por meio de corticotomia, até que entre em contato com a outra extremidade da falha óssea (Figura 6).

Cada uma das abordagens apresenta vantagens e desvantagens, que devem ser consideradas segundo as exigências de cada caso clínico em particular: o encurtamento agudo é indicado em casos de perdas em torno de $20 \%$ do comprimento original do segmento, que requeiram ou não reparo de nervos ou vasos, tendo como vantagens a redução e estabilização dos fragmentos por visão direta. Entre as desvantagens estão a diminuição temporária do comprimento do membro e o risco de angulação abrupta dos vasos com comprometimento da perfusão tecidual, nos encurtamentos mais extensos. O transporte mantém o comprimento e alinhamento das extremidades; a falha óssea é gradualmente preenchida por osso neoformado no "rastro" do fragmento transportado. A mais significativa desvantagem é a dificuldade de consolidação do fragmento transportado quando atinge a área de acoplagem com o segmento distal, podendo ser necessária abordagem cirúrgica para o avivamento das extremidades dos fragmentos ou mesmo para a adição de enxerto ósseo.

\section{Tratamento de fraturas e pseudoartroses}

Na fraturas dos ossos longos, particularmente nas expostas, em que a osteossíntese interna aumenta o risco de infecção, e nas cominutivas, o fixador de Ilizarov permite a redução e fixação estáveis dos fragmentos sem a necessidade de se abordar cirurgicamente o foco de fratura. As inúmeras possibilidades de configuração do sistema de fixação permitem alternativas individualizadas que se adaptem às condições específicas de cada caso (Figura 7).

No tratamento das fraturas, o objetivo a ser alcançado é o de estabelecer um sistema com máxima estabilidade entre os fragmentos da fratura, para que o processo de consolidação transcorra de modo eficiente. Para isso cada um dos principais fragmentos devem ser fixados em suas extremidades proximal e distal; este princípio básico é fundamental para que se neutralize o "braço 
de alavanca" que move os fragmentos quando apenas uma das extremidades é fixada.

As pseudoartroses, infectadas ou não, decorrentes de fixação insuficiente de fraturas de ossos longos são relativamente comuns na prática clínica. Em virtude da movimentação residual no foco, que impede a progressão do processo de consolidação, evoluem com a formação de um calo móvel. Neste tipo de pseudoartrose, denominada hipertrófica, as condições das partes moles e do próprio osso muitas vezes são obstáculos para qualquer outra eventual osteossíntese interna. A retirada do material de osteossíntese e fixação externa estável, com compressão no foco de pseudoartrose, são suficientes para se obter consolidação na maioria dos casos, sem a necessidade de adição de enxerto ósseo.

\section{Considerações finais}

O método de Ilizarov pode ser aplicado no tratamento de muitas patologias ortopédicas e no trauma. O conhecimento das inúmeras formas de se estruturar o fixador externo circular, de acordo com a necessidade de cada caso, e dos princípios biológicos que regem a regeneração tecidual, são fundamentais para sua correta utilização. A curva de aprendizado neste método é longa, sendo indicado iniciar com os casos mais simples até se adquirir suficiente experiência. Como outros métodos terapêuticos, não é desprovido de complicações, que devem ser prevenidas ou tratadas precocemente para que não interfiram no resultado.

\section{SUMMARY}

Based on osteogenesis by gradual distraction and circular external skeletal fixation, the Ilizarov method has made it possible to treat several complex orthopedic diseases. The article presents its principles and indications in Veterinary Medicine.

Key words: Ilizarov, osteogenesis.

\section{BIBLIOGRAFIA DE APOIO}

1 - ARONSON, J.; HARP, J.H. Mechanical considerations in using tensioned wires in a transosseous external fixation system. Clinical Orthopaedics, n.280, p.23-9, 1992.

2 - DAHL, M.T.; GULLI, B.; BERG, T. Complications of limb lengthening. A learning curve. Clinical Orthopaedics, n.301, p.10-8, 1994.

3 - FISCHGRUND, J.; PALEY, D.; SUTER, C. Variables affecting time to bone healing during limb lengthening. Clinical Orthopaedics, n.301, p.31-7, 1994.

4 - GUARNIERO, R. Erros comuns na utilização do método de Ilizarov. Revista Brasileira de Ortopedia, v.25, p. 31-4, 1990.

5 - ILIZAROV, G.A. The tension-stress effect on the genesis and growth of tissues. Part I - The influence of stability of fixation and soft-tissue preservation. Clinical Orthopaedics, n.238, p.249-81, 1989.

6 - ILIZAROV, G.A. The tension-stress effect on the genesis and growth of tissues. Part II - The influence of the rate and frequency of distraction. Clinical Orthopaedics, n.239, p. $263-85,1989$.

7 - ILIZAROV, G.A. Clinical application on the tension-stress effect for limb lengthening. Clinical Orthopaedies, n. 250, p. 826, 1990 .

8 - ILIZAROV, G.A. Transosseous osteosynthesis. Berlim: Springer-Verlag, 1992. 800p.

9 - KENWRIGHT, J.; WHITE, S.H. A historical review of limb lengthening and bone transport. Injury, v.24, suppl.2, p.9$19,1993$.
10 - LEWIS, D.D.; RADASCH, R.M.; BEALE, B.S.; STALLINGS, J.T.; LANZ, O.I.; WELCH, R.D.; SAMCHUKOV, M.L. Initial clinical experience with the IMEXTM circular external skeletal fixation system. Part I: Use in fractures and arthrodeses. Veterinary and Comparative Orthopaedics and Traumatology, v.12, p.108-17, 1999.

11 - LEWIS, D.D.; RADASCH, R.M.; BEALE, B.S.; STALLINGS, J.T.; WELCH, R.D.; SAMCHUKOV, M.L.; LANZ, O.I. Initial clinical experience with the IMEX ${ }^{\mathrm{TM}}$ circular external skeletal fixation system. Part II: Use in bone lengthening and correction of angular and rotational deformities. Veterinary and Comparative Orthopaedics and Traumatology, v.12, p.118-27, 1999.

12 - MARCELLIN-LITTLE, D.J.; FERRETI, A.; ROE, S.C.; DeYOUNG, D.J. Hinged Ilizarov external fixation for correction of antebrachial deformities. Veterinary Surgery, v.27, p.231-245, 1998

13 - PISTANI, J.R.; DAVID, E.; REDONDO, A. Historia y evolución de los tutores externos. In: PISTANI, J.R. Curso Taller: pasado, presente y futuro de los fijadores externos en ortopedia y traumatología. Capital Federal: Facultad de Ciencias Veterinarias U.B.A., 1993, p.3-6.

14 - ROSSI, J.D.M.B.A.; LEIVAS, T.P.; MORÉ, A.D.O.; CAFALLI, F.A.S.; FERRARESI, C.G.; ALMEIDA, F.C.R. Estudo crítico dos anéis de Ilizarov. Revista Brasileira de Ortopedia, v.25, p.373-6, 1990 .

15 - TOMMASINI, D.M. Case report: three cases of jaw lengthening to cure severe retragnotism in dogs. Veterinary Surgery, v.21, p.247, 1992 . 